Article

\title{
Toxoplasma GRA16 Inhibits NF-kB Activation through PP2A-B55 Upregulation in Non-Small-Cell Lung Carcinoma Cells
}

\author{
Seung-Hwan Seo ${ }^{1}$, Sang-Gyun Kim ${ }^{1}$, Ji-Hun Shin ${ }^{1}$, Do-Won Ham ${ }^{1}$ and Eun-Hee Shin ${ }^{1,2, *(1)}$ \\ 1 Department of Tropical Medicine and Parasitology, Seoul National University College of Medicine, \\ and Institute of Endemic Diseases, Seoul 03080, Korea; stopsh23@naver.com (S.-H.S.); \\ 0949kim@naver.com (S.-G.K.); charisma4395@naver.com (J.-H.S.); gkaehdnjs@daum.net (D.-W.H.) \\ 2 Seoul National University Bundang Hospital, Seongnam 13620, Korea \\ * Correspondence: ehshin@snu.ac.kr; Tel.: +82-2-740-8344
}

Received: 31 July 2020; Accepted: 8 September 2020; Published: 10 September 2020

\begin{abstract}
Nuclear factor kappa B (NF- $\mathrm{kB}$ ) activation is a well-known mechanism by which chemoresistance to anticancer agents is reported. It is well-known that irinotecan as a chemotherapeutic drug against non-small-cell lung carcinoma (NSCLC) has limited anticancer effect due to NF- $\mathrm{kB}$ activation. In this study, we propose the novel role of GRA16, a dense granule protein of Toxoplasma gondii, as an anticancer agent to increase the effectiveness of chemotherapy via the inhibition of NF-kB activation. To demonstrate this, H1299 cells were stably transfected with GRA16. The anticancer effects of GRA16 were demonstrated as a reduction in tumor size in a mouse xenograft model. GRA16 directly elevated B55 regulatory subunit of protein phosphatase 2A (PP2A-B55) expression in tumor cells, thereby decreasing GWL protein levels and ENSA phosphorylation. This cascade, in turn, induced PP2A-B55 activation and suppressed AKT/ERK phosphorylation and cyclin B1 levels, suggesting reduced cell survival and arrested cell cycle. Moreover, PP2A-B55 activation and AKT phosphorylation inhibition led to NF- $\mathrm{kB}$ inactivation via the reduction in inhibitory kappa B kinase beta (IKK $\beta$ ) levels, de-phosphorylation of inhibitor of kappa B alpha $(\mathrm{I} \kappa \mathrm{B} \alpha)$, and reduction in the nuclear transit of NF- $\mathrm{KB}$ p65. Furthermore, this molecular mechanism was examined under irinotecan treatment. The PP2A-B55/AKT/NF-kB p65 pathway-mediated anticancer effects were only induced in the presence of GRA16, but not in the presence of irinotecan. Moreover, GRA16 synergistically promoted the anticancer effects of irinotecan via the induction of the sub- $\mathrm{G}_{1}$ phase and reduction of cell proliferation. Collectively, irinotecan and GRA16 co-treatment promotes the anticancer effects of irinotecan via NF- $\mathrm{KB}$ inhibition and cell cycle arrest induced by GRA16, subsequently increasing the chemotherapeutic effect of irinotecan to NSCLC cells via NF- $k B$ inhibition.
\end{abstract}

Keywords: Toxoplasma GRA16; GRA16-stable cell line; non-small-cell lung carcinoma cells; H1299; PP2A-B55; irinotecan; NF-kB; cell cycle arrest; apoptosis; xenograft

\section{Introduction}

Lung cancer is among the most common cancers, and its prognosis remains very poor despite advances in surgical and chemo/radiation therapies aiming at reducing mortality $[1,2]$. Although radical surgery remains the best treatment for cancer, the importance of chemotherapy has been emphasized in personalized cancer therapy $[2,3]$. However, intrinsic or acquired resistance to chemotherapeutic agents is a common phenomenon and a major challenge in cancer treatment $[4,5]$. For non-small-cell lung carcinoma (NSCLC), chemotherapy is commonly administered using platinum 
analogs (cisplatin/carboplatin), gemcitabine, camptothecin analogs (irinotecan), paclitaxel, texanes, ABT-751, ixabepilone, vinorelbine, doxorubicin, etoposide, and pemetrexed, among others $[1,3,4]$. However, there have been reports of chemoresistance to all these drugs via mechanisms including active efflux of chemotherapeutic agents from tumor cells, modifications of drug targets, changes or mutations in mitotic checkpoint signals, drug sequestration, detoxification of cytotoxic agents, activation of nuclear factor kappa B (NF-kB), and enhanced DNA repair [1,3,4,6-8]. Similarly, NSCLC chemoresistance is typically associated with mutations in tumor suppressor $\mathrm{p} 53$. These mutations are present in almost $50 \%$ of NSCLC cases $[2,4,5]$, necessitating the development of alternate and supplementary therapies to overcome chemoresistance. Moreover, NSCLC accounts for approximately $80 \%$ of all primary lung cancers, and its incidence is increasing every year. Therefore, novel therapeutic strategies are urgently warranted to overcome NSCLC chemoresistance [2]. Among the chemotherapy options available without targeting the p53 effect, the cytotoxic agent irinotecan (CPT-11), a semisynthetic analog of camptothecin, has been used for NSCLC chemotherapy [1,3,4,6,7]. This drug inhibits topoisomerase-I activity, thereby reducing cell proliferation by regulating DNA replication $[8,9]$. NF- $\mathrm{kB}$ activation, a cause of the potential resistance mechanisms of CPT-11, limits the use of this drug as an anticancer agent $[1,8]$. Given the importance of CPT- 11 , which is a first-line chemotherapeutic agent for various types of cancers, supplementary agents that overcome CPT- 11 chemoresistance and NF- $\mathrm{kB}$ activation should be developed.

We recently reported the anticancer effects of dense granule protein 16 (GRA16) of Toxoplasma gondii in mouse xenograft models of GRA16-stable hepatocellular carcinoma (HCC) [10]. GRA16 increased the nuclear localization of phosphatase, tensin homolog (PTEN), and p53-dependent apoptosis by binding with herpes virus-associated ubiquitin-specific protease (HAUSP) in HCC cells [10]. However, functional studies of GRA16 in host cells revealed its interactions with two host cell enzymes, namely HAUSP and the B55 regulatory subunit of protein phosphatase 2A (PP2A-B55) [10-12]. Therefore, the anticancer mechanisms of GRA16 may be associated with its effects on the HAUSP/PTEN/p53 and PP2A/AKT/NF- KB pathways [10-12]. T. gondii is an intracellular parasite that infects multiple organs and tissues. During infection, it regulates host immunity in favor of its own survival $[2-4,13,14]$. As mentioned above, an immunomodulatory molecule of $T$. gondii (GRA16) may be a promising anticancer agent for inducing p53 activation. However, because GRA16 regulates other enzymes with PP2A-B55 binding, we determined whether GRA16 controlled NF- $\mathrm{kB}$ in association with PP2A-B55 and investigated its effects on the chemoresistance of irinotecan related with NF-kB activation in p53-mutant NSCLCs.

PP2A is a master cell cycle regulator acting as a gatekeeper from mitotic entry to exit. It decreases cell survival by inhibiting AKT phosphorylation, thereby acting as a crucial regulator of the NF- $\kappa$ B feedback loop [11-13,15]. AKT regulates the transcriptional activity of NF- $\mathrm{KB}$ by inducing the phosphorylation and subsequent degradation of its endogenous inhibitor $\kappa B$ (I $\kappa B$ ) [15]. Accordingly, the negative regulator of AKT represses NF-kB-dependent transcription [15]. PP2A-B55 deficiency is associated with poor prognoses of patients with cancer [16,17]. Moreover, many malignant tumors exhibit constitutive NF-KB activation that allows malignant cells to escape apoptosis by maintaining inflammatory microenvironments and inducing various oncogenic mutations [7-9]. In a mouse model of NSCLC, treatment with various NF- $\mathrm{kB}$ inhibitors prolonged survival $[7,9]$. A combination of anticancer drugs with NF-kB inhibitors may increase the chemosensitivity of cancer cells. In particular, NF- $\mathrm{kB}$ is a major driver of cell survival as well as a mediator of lung carcinogenesis; therefore, it can serve as a target for lung cancer prevention and therapy $[1,6]$. The resistance of NSCLC to irinotecan is well-known, and inhibition of NF-kB activation augments irinotecan-induced apoptosis $[7,16]$. 
In the present study, we considered the GRA16/PP2A-B55/AKT/NF-kB pathway as an anticancer target and established a stable model expressing GRA16 using H1299 cells, which are p53-null NSCLC cells. Using this model, we investigated chemoresistance to irinotecan, which does not inhibit NF- $\mathrm{kB}$ activity. In particular, we observed that GRA16 increased PP2A-B55 expression levels, resulting in cell cycle arrest and apoptosis. We further investigated the roles of the PP2A-B55/AKT/NF- $\mathrm{kB}$ pathway and demonstrated the unique anticancer effects of GRA16, including inhibition of NF- $\mathrm{KB}$ nuclear translocation and AKT activation. Our data suggest that GRA16 has potential anticancer effects via NF-KB inhibition, even though irinotecan was also used for treatment.

\section{Results}

2.1. Binding of GRA16 and PP2A-B55 in GRA16-Expressing Stable H1299 Cells and Tumor Suppression in Xenograft Mice Transplanted with GRA16-Expressing Cells

To investigate the anticancer effects of GRA16 without p53, the GRA16-expressing plasmid with the GRA16 (1518 bp) gene incorporated into the pBABE-HA II-Vector was transfected into p53-null H1299 cells (Figure 1A,B). GRA16 protein expression was confirmed using Western blotting, which showed higher GRA16 protein expression in the nucleus than in the cytoplasm (Figure 1C,D). GRA16 cells showed high PP2A-B55 expression at both mRNA and protein levels throughout the $60 \mathrm{~h}$ study period, during which GRA16 expression was maintained (Figure 1E-J). The red fluorescence images in Figure 1E depict PP2A-B55 protein expression in the cytoplasm and nucleus at $48 \mathrm{~h}$. Likewise, the relative mRNA expression of the PP2A-B55 gene PPP2R2B was significantly higher in GRA16 cells than in control and vector cells after $48 \mathrm{~h}(p<0.05$, Figure 1F). The increased PP2A-B55 expression in GRA16 cells was supported by change in the expression levels of the transcriptional factors of the B55 subunit, including cAMP responsive element binding protein 1 (CREB1), stable protein 1 (SP1), and transcription factor AP-4 (TFAP4) (Figure 1G). The expression levels of two transcriptional factors-CREB1 and SP1—which increase the promotor activity of the B55 subunit, were significantly increased in GRA16 cells ( $p<0.05$, Figure 1G). Meanwhile, the expression level of another transcription factor, TFAP4, which is a negative regulator, was significantly decreased in GRA16 cells $(p<0.05$, Figure 1G). With steady expression of GRA16 and PP2A-B55 throughout the experimental period, our co-immunoprecipitation (Co-IP) assay revealed a sustained binding interaction between GRA16 and PP2A-B55 in cells (Figure 1H-K). To determine whether GRA16 expression has anticancer effects, changes in the tumor growth and body weights of nude mice xenograft models were monitored for 44 days before being sacrificed. Mice xenografts with control and vector cells exhibited a gradual increase in tumor volume and weight; however, the tumor volume and weight of mice xenografts with GRA16 cells were significantly lower than those of mice xenografts with control and vector cells $(p<0.05$, Figure $1 \mathrm{~L}, \mathrm{~N})$. Simultaneously, the body weights of xenograft mice were similar in all the three groups, suggesting that reduced tumor growth in the GRA16 group was unrelated to body weight changes (Figure 1M). We revealed novel results that GRA16 continuously increases PP2A-B55 expression in cells and that it is related to tumor reduction in NSCLC. 


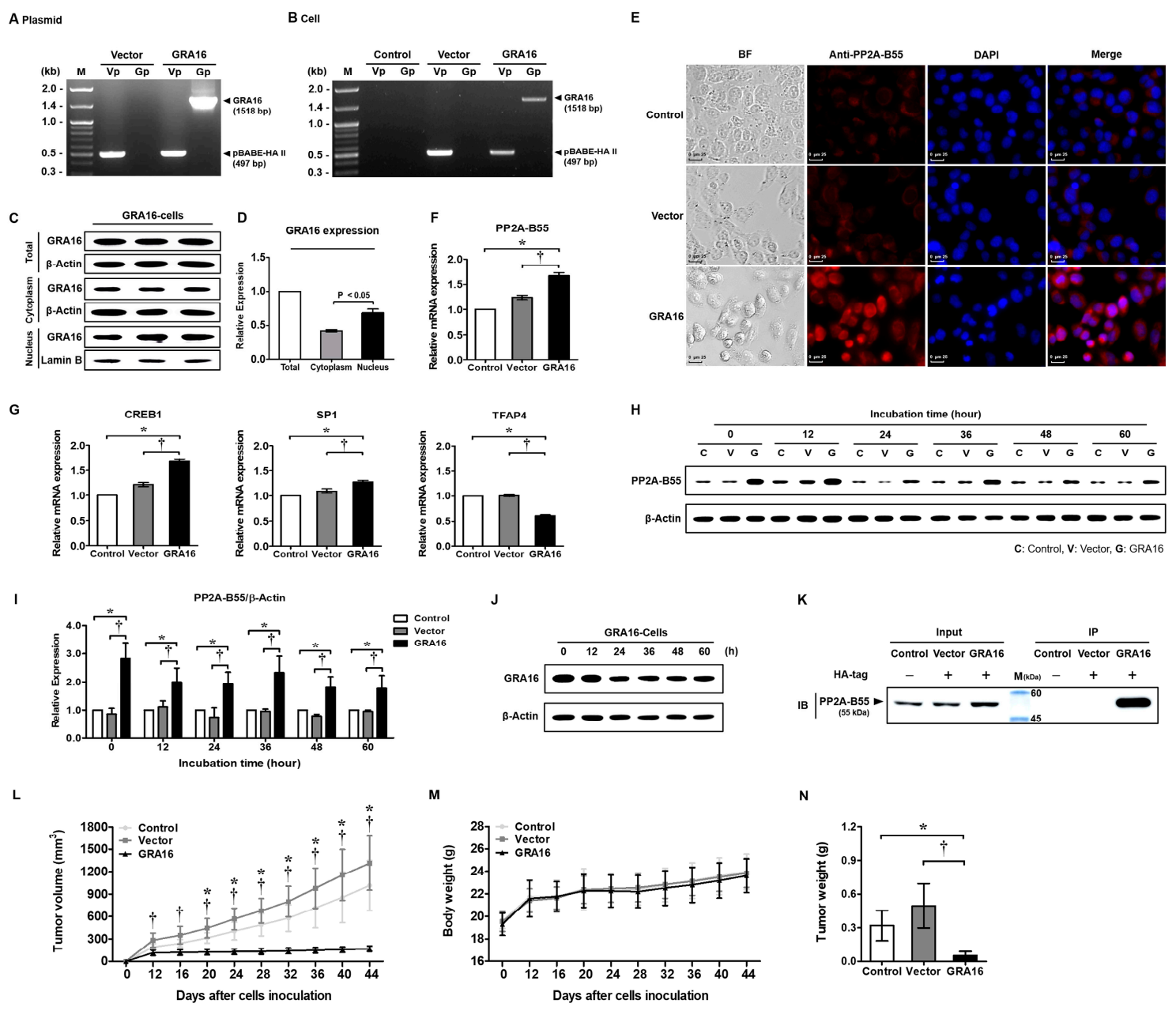

Figure 1. Production of GRA16-stable H1299 cells, binding between GRA16 and PP2A-B55, and anticancer effect in xenograft mice transplanted with GRA16 cells. (A) Polymerase chain reaction (PCR) results of the purified pBABE-HA II plasmid (Vector) and GRA16 gene-inserted pBABE-HA II plasmid (GRA16) using primers Vp (vector primer) and Gp (GRA16 primer). (B) PCR results of cells (control, vector, and GRA16 cells) using primers (Vp or Gp). (C) Western blots showing GRA16 distribution in cell fractions (cytoplasm and nucleus). (D) Relative protein expression of HA-tagged GRA16 between the cytoplasm and nucleus. (E) Immunofluorescence assay (IFA) for PP2A-B55 expression in control, vector, and GRA16 cells. BF: bright field, DAPI: nucleus staining. Scale bar represents $25 \mu \mathrm{m}$. (F) Relative mRNA expression levels of PP2A-B55. (G) Gene expression levels of the transcriptional factors (CREB1, SP1, and TFAP4) in vector and GRA cells compared with control cells. (H) Western blot showing PP2A-B55 expression in control (C), vector (V), and GA16 cells (G) during $60 \mathrm{~h}$ after cell synchronization. (I) Differences in PP2A-B55 expression among control, vector, and GRA16 cells, with the expression value of control set at " 1 ". (J) Western blots confirming sustained GRA16 expression in GRA16 cells during the 60-h experiment period. (K) Co-immunoprecipitation (Co-IP) confirming the interaction between GRA16 and PP2A-B55. Input: immunostaining of PP2A-B55 in total protein before Co-IP analysis; IP: Western blots stained with anti-PP2A-B55 Ab for the protein fraction (GRA16) extracted using anti-HA tag $\mathrm{Ab}$ at $48 \mathrm{~h}$ of cell incubation. (L) Tumor sizes (tumor volumes were calculated as $\mathrm{A} \times \mathrm{B}^{2} / 2$ (A: length; B: width)). (M) Body weights. (N) Tumor weights. * significant at $p<0.05$ between control and GRA16 cells; ${ }^{+}$significant at $p<0.05$ between vector and GRA16 cells. 


\subsection{Effect of Irinotecan Treatment on the NF- $\mathrm{B} B$ Signaling Pathway and Drug Resistance Markers in NSCLC}

To determine if GRA16 can be used as a complement to NF-KB-mediated chemoresistance, we examined the chemoresistance of irinotecan, as reflected by NF- $\mathrm{KB}$ activation (Figure 2). The half-maximal inhibitory concentration $\left(\mathrm{IC}_{50}\right)$ of irinotecan was $16.64 \pm 1.31 \mu \mathrm{M}$ (Figure $2 \mathrm{~A}, \mathrm{~B}$ ), based on which irinotecan concentration for subsequent experiments was set at $17 \mu \mathrm{M}$. NF- $\mathrm{kB}$ activation was investigated according to the expression levels of inhibitory kappa $B$ kinase beta (IKK $\beta$ ), ratios of phospho-inhibitor of kappa B alpha $(\mathrm{p}-\mathrm{I} \kappa \mathrm{B} \alpha) / \mathrm{I} \kappa \mathrm{B} \alpha$, and translocation of NF- $\kappa \mathrm{B}$ from the cytoplasm to the nucleus (Figure $2 \mathrm{C}, \mathrm{D}$ ). Irinotecan treatment increased IKK $\beta$ expression and IKB $\alpha$ phosphorylation but simultaneously maintained the nuclear localization of NF- $\mathrm{KB}$ (Figure 2D). This result suggests that irinotecan does not inhibit NF- $\mathrm{kB}$ activation. Moreover, the expression levels of resistance markers related to the augmentation of NF- $\mathrm{kB}$ activity, such as $\mathrm{Cbp} / \mathrm{p} 300$ interacting transactivator with Glu/Asp-rich carboxy-terminal domain 2 (CITED2), ATP-binding cassette subfamily G member 2 (ABCG2), and Catenin alpha like 1 (CTNNAL1), increased over time following irinotecan treatment (Figure 2E, $p<0.05$ ). However, the expression levels of breast cancer susceptibility gene 1 (BRCA1), a cancer-inhibiting gene related to NF- $\mathrm{kB}$ inhibition, were decreased following irinotecan treatment (Figure 2E, $p<0.05$ ). These results strongly suggest that the anticancer effects of irinotecan are limited because it does not inhibit NF- $\mathrm{kB}$ activity, and this may be an important reason for chemoresistance to irinotecan.

A

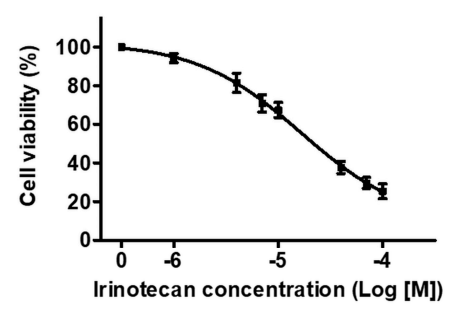

B

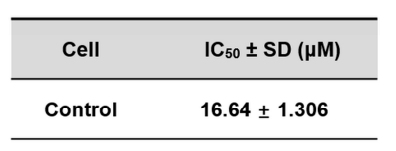

C Irinotecan (+)

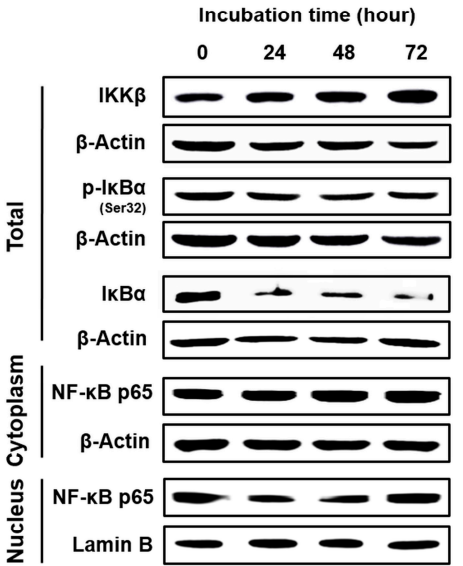

D Irinotecan (+)

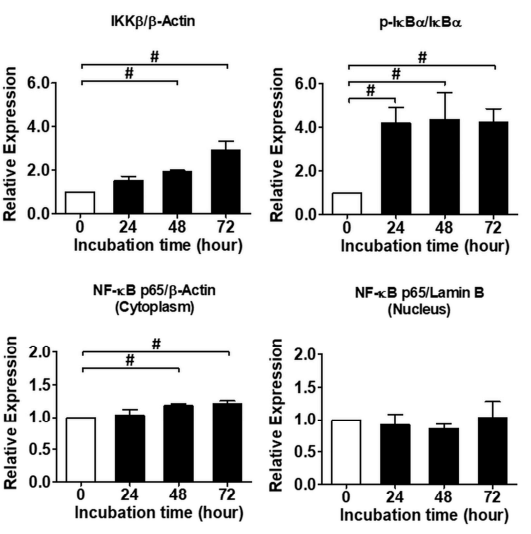

E Irinotecan (+)
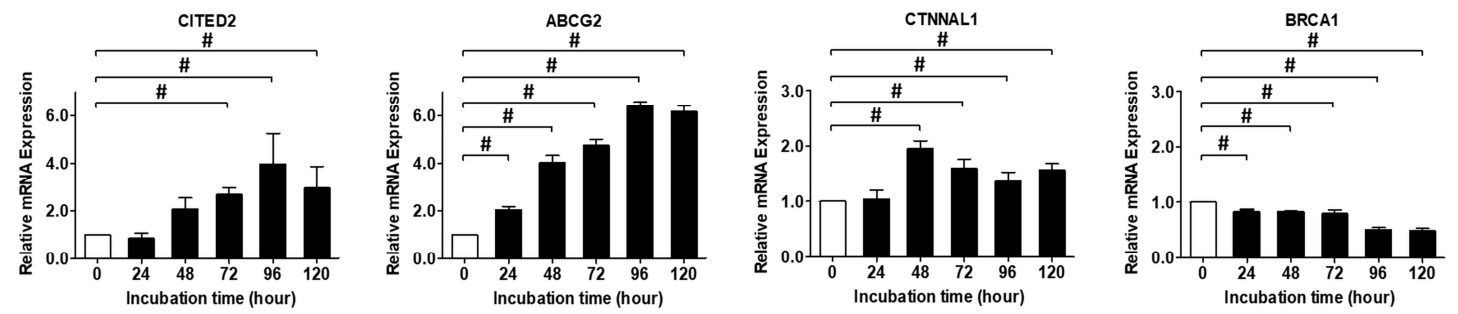

Figure 2. $\mathrm{IC}_{50}$ of irinotecan in NSCLC cells (H1299) and its effects on NF- $\mathrm{kB}$ signaling and drug resistance markers. (A) When cells were treated with 0-100 $\mu \mathrm{M}$ of irinotecan, the viability (\%) decreased in an irinotecan concentration-dependent manner. (B) $\mathrm{IC}_{50}$ of irinotecan was $16.64 \mu \mathrm{M}$. (C) Western blots of IKK $\beta, \mathrm{p}-\mathrm{I} \kappa \mathrm{B} \alpha, \mathrm{I} \kappa \mathrm{B} \alpha$, and NF- $\kappa \mathrm{B}$ p65 after treatment with $17 \mu \mathrm{M}$ irinotecan. (D) Relative protein expressions of IKK $\beta, \mathrm{p}-\mathrm{I} \kappa \mathrm{B} \alpha / \mathrm{I} \kappa \mathrm{B} \alpha$, and NF- $\kappa \mathrm{B}$ p65 (cytoplasm and nucleus) compared with those before treatment (1.0 fold). (E) Changes in drug resistance (CITED2, ABCG2, and CTNNAL1) and sensitivity (BRCA1) after irinotecan treatment. \# significant difference at each time point after irinotecan treatment $(p<0.05)$. 
2.3. GRA16 Regulates Cell Cycle Arrest and Apoptosis via the PP2A-B55/GWL/ENSA Pathway and Cyclin B1, $A K T$ and ERK Dephosphorylation

GRA16-mediated increases in PP2A-B55 expression levels are required for GWL dephosphorylation and lead to ENSA dephosphorylation. When activated, GWL induces ENSA phosphorylation, which inhibits PP2A-B55 activity via direct interactions. In these experiments, increased PP2A-B55 levels were followed by reduced GWL protein levels in GRA16 cells (Figure 3A,B, $p<0.05$ ). Following the cascade reaction, ENSA phosphorylation significantly decreased in GRA16 cells (Figure 3A,B, $p<0.05$ ), possibly leading to sustained PP2A-B55 activity and mitosis inhibition. As a specific marker for $\mathrm{G}_{2} / \mathrm{M}$ transition, cyclin B1 is necessary for entry into mitosis. As key regulators of PP2A-B55 activity, GWL and ENSA were inhibited by GRA16 but not by irinotecan (Figure 3C,D). Cyclin B1 expression was reduced irrespective of irinotecan treatments in GRA16 cells (Figure 3A,C). The decrease in cyclin B1 expression was greater with GRA16 and irinotecan than with GRA16 alone $(0.18 \pm 0.05$ times vs. $0.55 \pm 0.06$ times, respectively (Figure 3B,D)). Phosphorylated AKT and ERK signaling promote cellular survival and inhibit apoptosis. These processes are important and well-studied regulatory hallmarks of cancers and are required for uncontrolled cell growth. Therefore, the PP2A-mediated regulation of AKT and ERK is likely central to the anticancer effects of GRA16. As expected, GRA16 cells showed decreased AKT phosphorylation $(p<0.05$, Figure 3E-H). However, ERK phosphorylation was not changed by GRA16 alone (Figure 3E,F) but was decreased by the synergistic action of GRA16 and irinotecan $(p<0.05$, Figure 3G,H). These molecular signals indicate that GRA16, which augments PP2A protein expression, shows anticancer effect via the decrease in cell survival and the increase in $G_{2} / M$ arrest in GRA16-expressing NSCLC cells.

\subsection{Induction of Cell Apoptosis and Cell Cycle Arrest and Simultaneous Inhibition of Cell Proliferation by GRA16}

Because the anticancer effect is related to the inhibition of cancer cell proliferation as well as cell death, we determined the effects of GRA16 on cell apoptosis by FACS analysis and cell proliferation using the CCK-8 assay and trypan blue exclusion test before and after irinotecan treatments (Figure 4A-D). Our results show that GRA16 cells induce cell apoptosis based on the significant increase in apoptotic and necrotic cells stained with annexin $\mathrm{V}$ and propidium iodide (PI) compared with control and vector cells $(p<0.05$, Figure $4 \mathrm{~A})$. The increase in apoptotic cells was higher after irinotecan treatment $(p<0.05$, Figure 4B). With the increase in apoptotic and necrotic cells, GRA16 cells significantly lower cell proliferation compared with control and vector cells regardless of irinotecan treatment $(p<0.05$, Figure 4C). After irinotecan treatment, the proliferation of GRA16 cells was decreased further (Figure 4D). Moreover, in FACS analysis of cell cycle arrest (Figure 4E,F), GRA16 cells showed significantly increased $\mathrm{G}_{2} / \mathrm{M}$ arrest compared with cells of other groups (Figure $4 \mathrm{E}$ ). The $\mathrm{G}_{2} / \mathrm{M}$ arrest was further increased by irinotecan treatment in GRA16 cells, suggesting the synergistic effects of GRA16 and irinotecan (Figure 4F). Irinotecan treatment also led to significant increases in the proportions of cells in the sub- $\mathrm{G}_{1}$ phase in cells of all groups at $48 \mathrm{~h}$ after cell synchronization, suggesting increased apoptosis (Figure $4 \mathrm{~F}$ ). Moreover, the proportion of cells in the sub- $\mathrm{G}_{1}$ phase of cell cycle (\%) was higher in the GRA16 group $(18.20 \% \pm 1.85 \%)$ than in the control $(1.64 \% \pm 0.20 \%)$ and vector groups $(2.91 \% \pm 0.29 \%)$ (Figure $4 \mathrm{~F})$. These results indicate that GRA16 induces $\mathrm{G}_{2} / \mathrm{M}$ cell cycle arrest and that irinotecan treatment significantly accelerates entry into the apoptotic sub- $\mathrm{G}_{1}$ phase $(p<0.05$, Figure $4 \mathrm{~F})$. This synergistic effect of irinotecan and GRA16 could be exploited for treating NSCLC. 


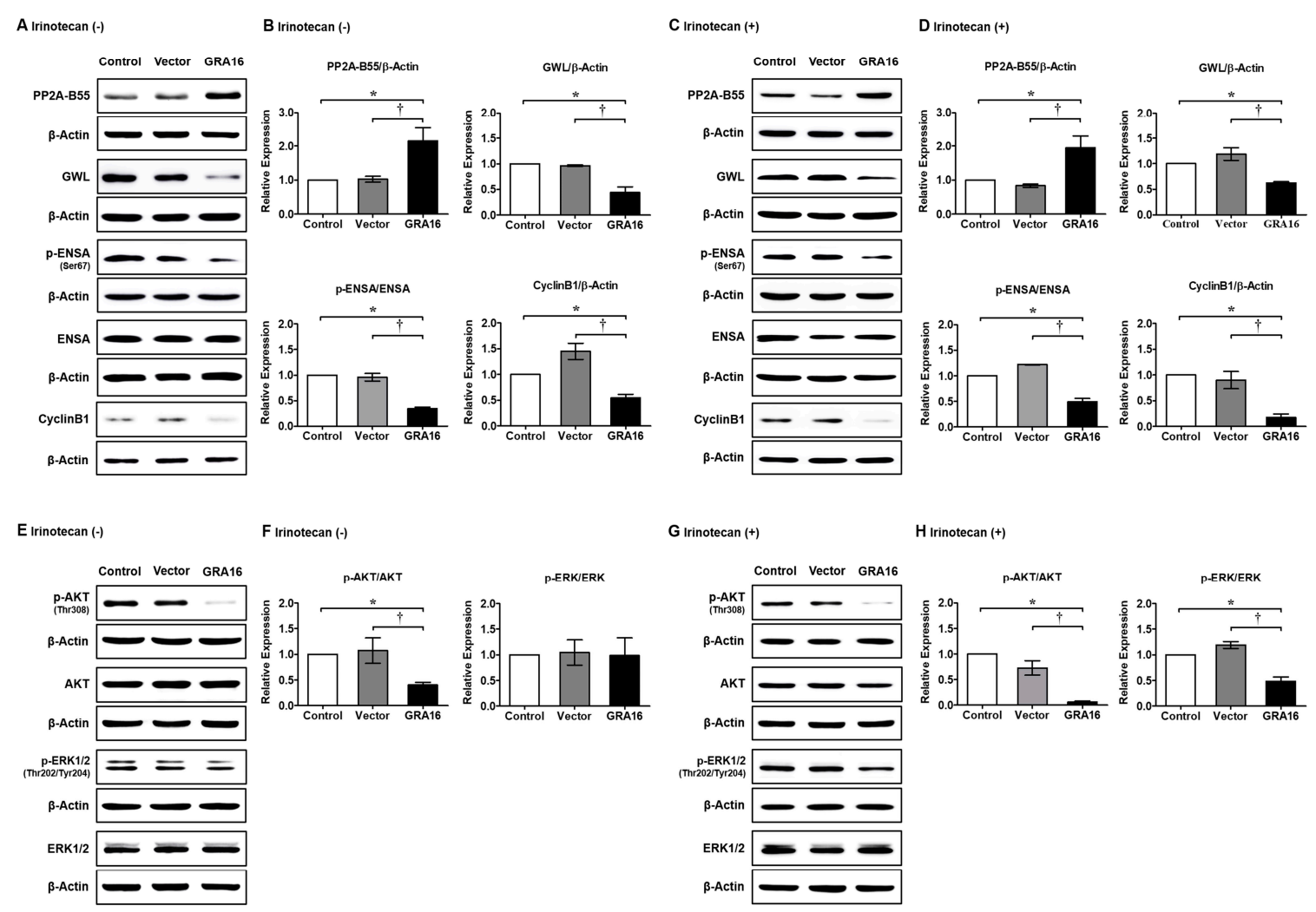

Figure 3. Inhibition in GWL and ENSA phosphorylation and cyclin B1 level and dephosphorylation of AKT and ERK by the augmentation of PP2A-B55 in GRA16 cells. (A) Western blots of PP2A-B55, GWL, p-ENSA, and cyclin B1 expression in cells without irinotecan treatment. (B) Relative expression levels of these proteins in vector and GRA16 cells compared with control cells. (C) Expression levels of each protein under irinotecan treatment compared with those in (A). (D) Relative expression levels of these proteins under irinotecan treatment compared with those in (B). (E) Western blots of p-AKT and p-ERK expression without irinotecan treatment. (F) Ratios of p-AKT/AKT and p-ERK/ERK expression without irinotecan treatment. (G) Western blots of $\mathrm{p}$-AKT and p-ERK expression under irinotecan treatment. (H) Ratios of p-AKT/AKT and p-ERK/ERK expression under irinotecan treatment. ${ }^{*}$ significant at $p<0.05$ between control and GRA16 cells; ${ }^{\dagger}$ significant at $p<0.05$ between vector and GRA16 cells.

\subsection{NF- $\kappa B$ Inhibition in NSCLC Cells in the Presence of GRA16 and/or Irinotecan}

To investigate the effects of GRA16 and/or irinotecan on NF- $k B$ activity, we examined changes in IKK $\beta$, ratios of $\mathrm{p}-\mathrm{I} \kappa \mathrm{B} \alpha / \mathrm{I} \kappa \mathrm{B} \alpha$, and NF- $\mathrm{kB}$ p65 nuclear localization in control, vector, and GRA16 cells using immunofluorescence and Western blotting (Figure 5). In immunofluorescence experiments, intracellular NF- $\mathrm{KB}$ p65 expression and NF-KB nuclear localization in GRA16 cells were decreased compared with those in control and vector cells (Figure 5A,B). In Western blotting, GRA16 cells showed significantly decreased IKK $\beta$ levels, $\mathrm{p}-\mathrm{I} \kappa \mathrm{B} \alpha / \mathrm{I} \kappa \mathrm{B} \alpha$ ratio, and nuclear NF- $\kappa \mathrm{B}$ p65 expression regardless of irinotecan treatment $(p<0.05$, Figure $5 \mathrm{C}-\mathrm{F})$. These results indicate that irinotecan itself does not affect NF- $\mathrm{KB}$ p65 expression regardless of irinotecan treatment. Therefore, as an inhibitor of NF- $\mathrm{kB}$ activation, GRA16 may overcome resistance to irinotecan chemotherapy, potentially leading to changes in the expression levels of drug resistance markers (Figure $5 \mathrm{G}, \mathrm{H}$ ). In our results, the relative mRNA expression of the drug resistance marker genes $A B C G 2$ and CTNNAL1 were significantly reduced in GRA16 cells $(p<0.05$, Figure 5G,H). The cancer suppressor gene BRCA1 was highly expressed in GRA16 cells compared with that in control and vector cells $(p<0.05$, Figure 5G,H). The expression levels of these marker genes, which govern NF-KB activities, were affected by GRA16, but not by irinotecan in NSCLC cells, suggesting that GRA16 prevents the development of drug resistance (Figure 5G,H). On the other hand, when GRA16 inhibits NF-kB p65 nuclear localization, 
NF- $\mathrm{kB}$-target gene expressions would be affected because NF- $\mathrm{KB}$ as a transcriptional factor can be inactivated. To prove this, we investigated the relative mRNA expression of apoptosis-related genes among the various NF-kB-target genes (Figure 5I,J). At this time, antiapoptosis-related genes (c-MYC and $B C L-2)$ were reduced and proapoptosis-related genes (BAX and ARHGEF7) were conversely increased regardless of irinotecan treatment $(p<0.05$, Figure 5I,J). These results highlight that GRA16 regulates the NF-kB target gene expression related with apoptosis via the inhibition of NF- $\mathrm{kB}$ p65 nuclear localization.

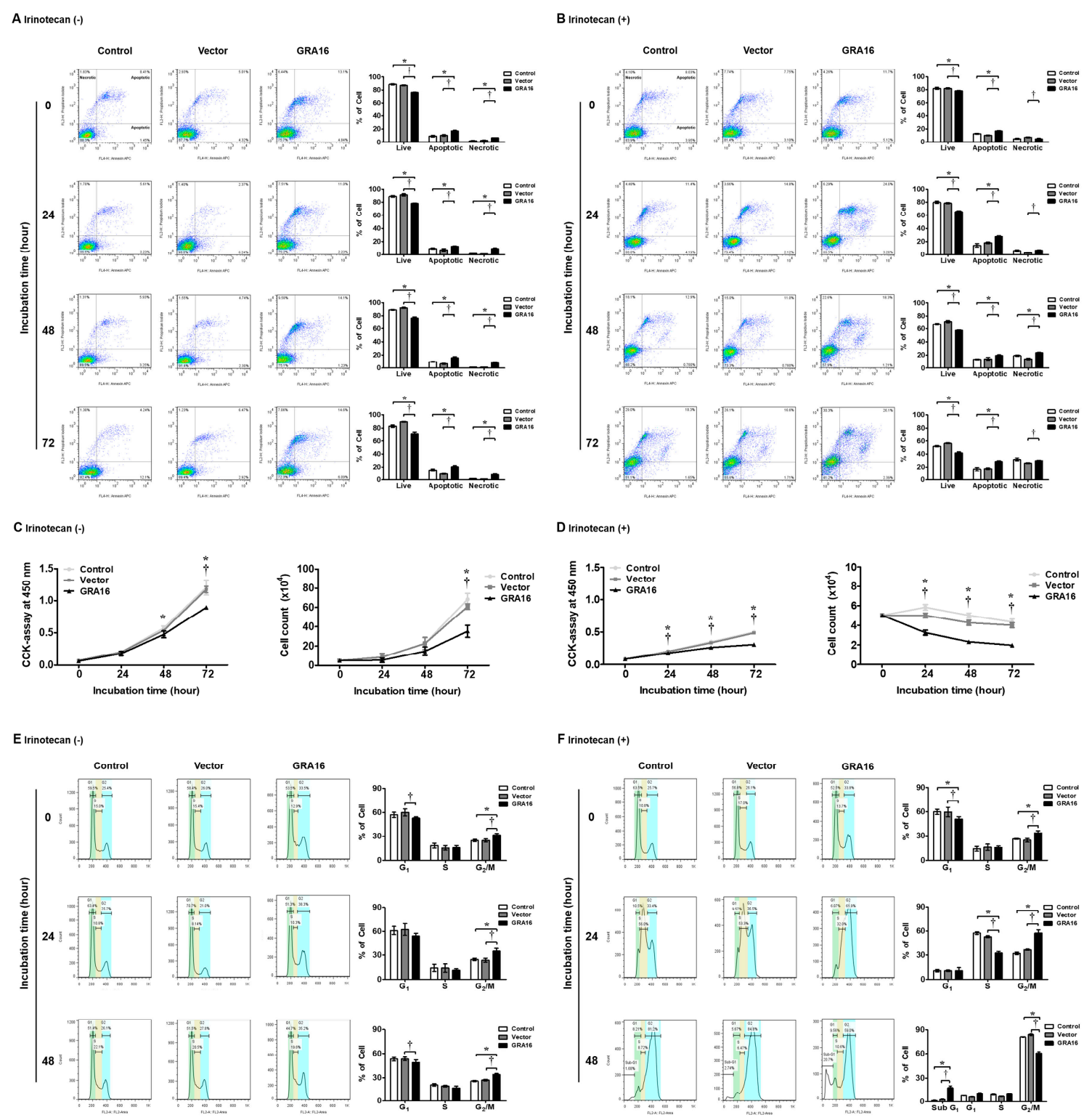

Figure 4. Effects of GRA16 and irinotecan on the induction of apoptosis and cell cycle arrest in non-small-cell lung carcinoma (NSCLC). Cell viability, cell cycle arrest, and cell apoptosis were investigated in GRA16 cells before and after irinotecan treatment using the CCK-8 assay and FACS analysis. (A) Annexin V and propidium iodide (PI) staining without irinotecan treatment. (B) Annexin $\mathrm{V}$ and PI staining under irinotecan treatment. (C) Cell viability and cell count (trypan blue exclusion test) without irinotecan treatment. (D) Cell viability and cell count under irinotecan treatment. (E) Cell cycle analysis via FACS without irinotecan treatment. (F) Cell cycle analysis via FACS under irinotecan treatment. ${ }^{*}$ significant at $p<0.05$ between control and GRA16 cells; ${ }^{\dagger}$ significant at $p<0.05$ between vector and GRA16 cells. 

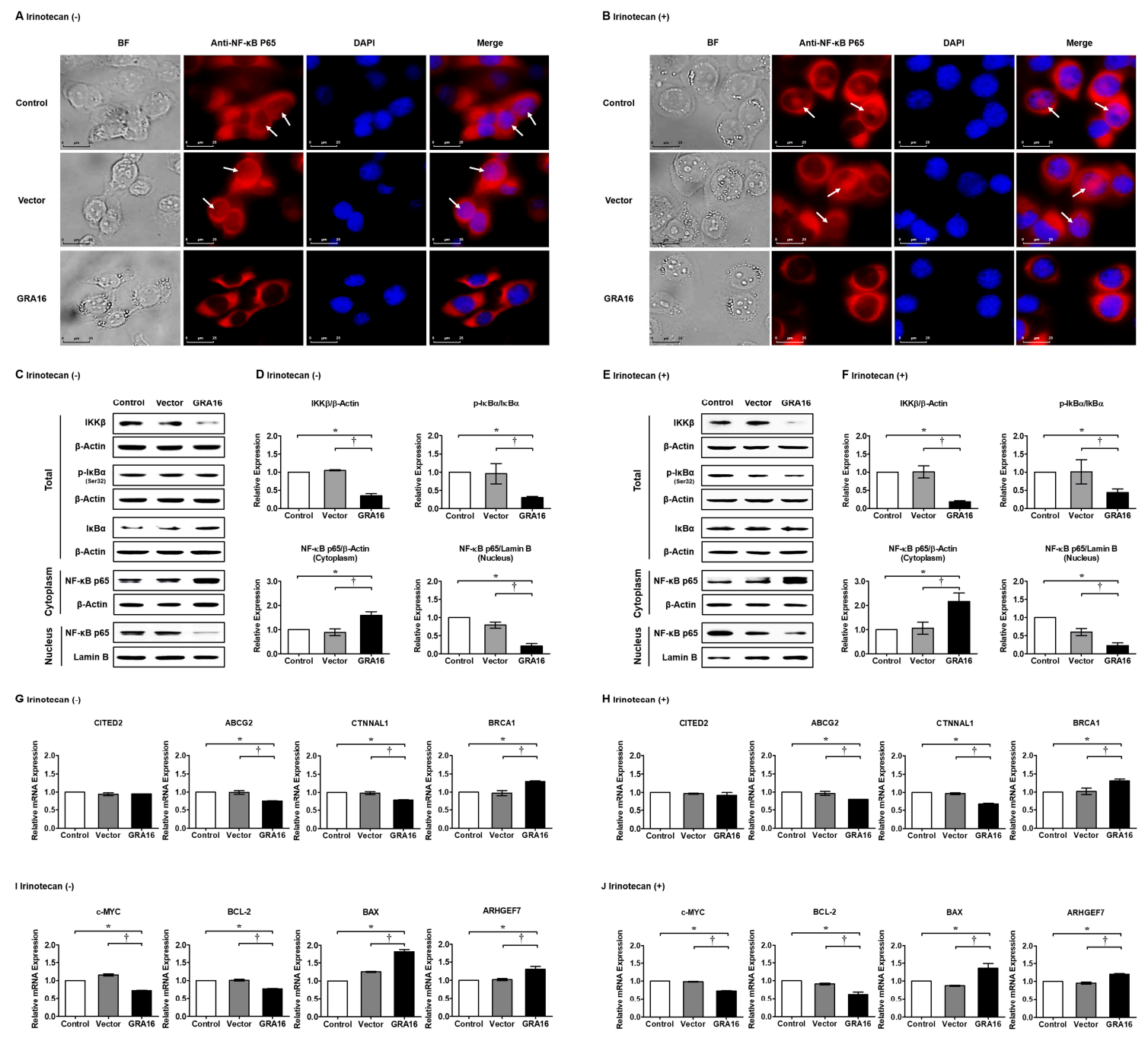

Figure 5. NF- $\mathrm{B}$ inhibition induced by GRA16 in NSCLC regardless of irinotecan treatment. Immunofluorescence assay (IFA) for NF- $\mathrm{B}$ B expression in control, vector, and GRA16 cells without (A) and with (B) irinotecan treatment. BF: bright field, DAPI: nucleus staining. White arrows represent $\mathrm{NF}-\kappa \mathrm{B}$ p65 protein in the nucleus. Scale bar represents $25 \mu \mathrm{m}$. Western blots of IKK $\beta, \mathrm{p}-\mathrm{I} \kappa \mathrm{B} \alpha$, $\mathrm{I} \kappa \mathrm{B} \alpha$, and NF- $\kappa \mathrm{B}$ p 65 without $(\mathrm{C})$ and with (E) irinotecan treatment and their relative expressions of protein in the cytoplasm and nucleus without (D) and with (F) irinotecan treatment. Changes in drug resistance (CITED2, ABCG2, and CTNNAL1) and sensitivity (BRCA1) markers without (G) and with (H) irinotecan treatment. Changes in NF- $\mathrm{KB}$ target genes related with antiapoptosis (c-MYC and $B C L-2)$ and proapoptosis (BAX and ARHGEF7) markers without (I) and with (J) irinotecan treatment. * significant at $p<0.05$ between control and GRA16 cells; ${ }^{\dagger}$ significant at $p<0.05$ between vector and GRA16 cells.

\subsection{GRA16-Induced Apoptosis and NF-אB Inativation Was Reversed by the PP2A Inhibitor LB-100}

The experiments described above showed that GRA16 increases PP2A-B55 and induces PP2A-B55-mediated AKT dephosphorylation, leading to NF-KB inhibition. To understand PP2A-B55 dependency on NF-KB inhibition, we treated control, vector, and GRA16 cells with the specific PP2A inhibitor LB-100 (Figure 6). In these experiments, the IC 50 of LB-100 for PP2A was $7 \mu \mathrm{M}$ (Figure 6A). In the presence of LB-100, cell proliferation and NF-KB activity were not reduced in GRA16 cells (Figure $6 \mathrm{~B}, \mathrm{C}$ ). Similarly, the relative protein expression levels of $\mathrm{p}-\mathrm{AKT}$, IKK $\beta$, and $\mathrm{p}-\mathrm{I} \kappa \mathrm{B} \alpha$ were slightly increased in GRA16 cells, and the nuclear translocation of NF- $\mathrm{kB}$ was no longer inhibited (Figure $6 \mathrm{D}, \mathrm{E}$ ). 
A
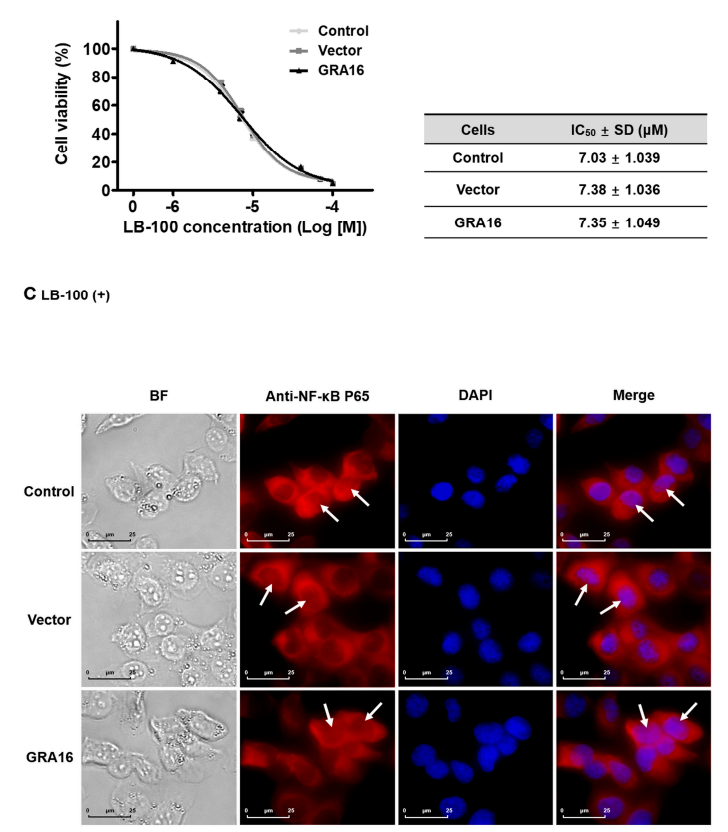

B LB-100 (+)
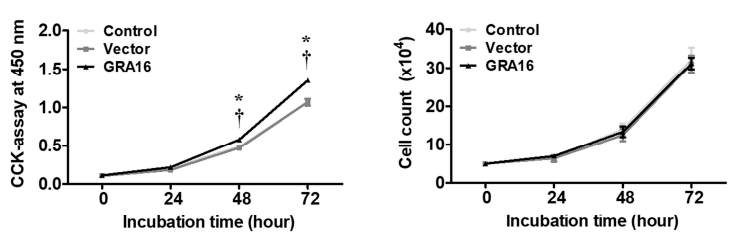

D LB-100 (+)

ELB-100 (+)

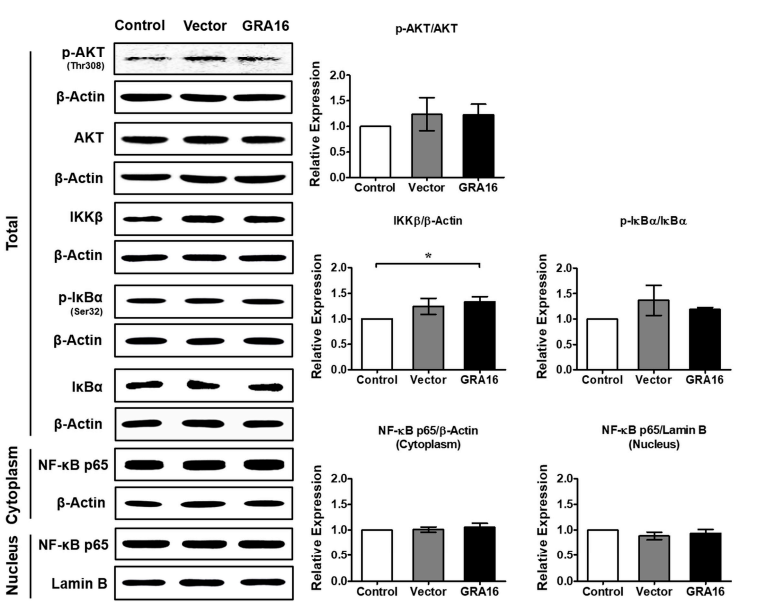

Figure 6. Treatment with LB-100, a PP2A inhibitor, reverses the reduced cell viability, AKT dephosphorylation, and NF-kB inactivation induced in GRA16 cells. (A) IC 50 of LB-100 in NSCLC cells. (B) Cell viability and total cell count after treatment with $7 \mu \mathrm{M}$ (as determined by the $\mathrm{IC}_{50}$ result) LB-100. (C) Immunofluorescence images of NF- $\kappa$ B distribution in the cytoplasm and nucleus. BF: bright field, DAPI: nucleus staining. White arrows represent NF- $\mathrm{B}$ p65 protein in the nucleus. Scale bar represents $25 \mu \mathrm{m}$. Western blots of $\mathrm{p}-\mathrm{AKT}, \mathrm{AKT}, \mathrm{IKK} \beta, \mathrm{p}-\mathrm{I} \kappa \mathrm{B} \alpha, \mathrm{I} \kappa \mathrm{B} \alpha$, and NF- $\mathrm{B}$ p 65 in control, vector, and GRA16 cells (D) and their relative expressions (E). * significant at $p<0.05$ between control and GRA16 cells; ${ }^{\dagger}$ significant at $p<0.05$ between vector and GRA16 cells.

\section{Discussion}

PP2A-B55 negatively regulates AKT signaling; therefore, it is referred to as a tumor suppressor [17,18]. PP2A inactivation and AKT activation are the key drivers of cell survival and drug resistance in lung cancer, particularly in NSCLC $[17,18]$. The cellular PP2A inhibitors oncoprotein I2PP2A (SET) and cancerous inhibitor of PP2A (CIP2A) affect drug resistance and cell survival in many cancers; subsequently, CIP2A downregulation and SET inhibition activate PP2A and restore chemosensitivity to cisplatin as well as reduce tumor burden $[17,18]$. Accordingly, therapeutic strategies targeting PP2A have become increasingly important. PP2A also regulates AKT and NF- $\mathrm{kB}$ via the ensuing signaling cascades [12,17]. The downregulation of the AKT/NF- $\mathrm{KB}$ pathway is partly associated with cell growth inhibition and apoptosis induction by the soybean isoflavonoid genistein $[19,20]$. Genistein-induced NF- $\mathrm{KB}$ inactivation was mediated via the AKT signaling pathway in breast cancer cells [20]. In this study, GRA16 could be considered as a novel AKT/NF-kB inhibitor, similar to genistein, because it inhibits AKT/NF-KB signaling in NSCLC via p53-independent pathways. Similar to the effects of genistein in breast cancer cells, the anticancer effects of GRA16 were associated with the induction of AKT and ERK dephosphorylation, followed by cell cycle arrest, apoptosis, sub- $\mathrm{G}_{1}$ phase arrest, and NF- $\mathrm{KB}$ inhibition in NSCLC cells under the condition that p53 signaling was not involved. Therefore, these properties of GRA16 could be exploited to overcome chemoresistance to irinotecan, which is widely used as a chemotherapeutic agent for NSCLC.

T. gondii has shown anticancer effects against various cancer types and diverse antigenic proteins [21-23]. As a biological property, T. gondii evades or regulates host immunity to facilitate proliferation and maintenance of its life cycle $[24,25]$. This control of immunity during T. gondii 
infection has stimulated multiple investigations related to other immune diseases; as a result, T. gondii proteins have been considered therapeutic agents for other incurable diseases $[10,14,21-25]$. Regarding the original biological properties of GRA16 used in this study, dense granule proteins, such as GRA16, within the secretory vesicles of T. gondii participate in a membranous nanotubular network in parasitophorous vacuoles (PVs) that maintain intracellular parasitism in host cells $[10,13,14]$. Although the original roles of these proteins were restricted to PV maturation and parasite growth [13], roles in the modulation of host signaling pathways have since been described [13,14]. Furthermore, the anticancer effects of GRA16 reflect the binding of HAUSP and PP2A sites and the resulting regulation of cell cycle progression, proliferation, and apoptosis $[10,11,15,17,18]$. Herein, we present novel evidence showing that T. gondii GRA16 overcomes the limitations of the commonly used chemotherapeutic agent irinotecan by inhibiting NF- $k$ B activation. We showed that GRA16 regulates the PP2A-B55/AKT/NF- $\kappa$ B signaling cascade and that GRA16 can be applied as an alternative adjuvant therapeutic agent for reducing the chemoresistance of p53-mutant NSCLCs where irinotecan is used as a chemotherapeutic agent. Because AKT stimulates NF- $\mathrm{KB}$ activity by promoting the phosphorylation of IKB and p65/RelA via IKK and the inhibition of NF-kB p65 nuclear translocation also suggests NF-kB inactivation $[15,26]$, our results suggest that GRA16 prevents NF- $\mathrm{K} B$ activation and the subsequent expression of drug resistance markers by regulating PP2A-B55/AKT/NF- $\mathrm{B}$ signaling. As a result, GRA16 inhibits tumor growth in GRA16-expressing mouse xenografts. The underlying mechanism involves cell cycle arrest and apoptosis via PP2A-B55/AKT/NF- $\mathrm{B}$ signaling regulation. Taken together, these data show that GRA16 has a promising role as a novel AKT/NF- $\mathrm{B}$-regulating adjuvant chemotherapy for irinotecan-resistant NSCLCs. Meanwhile, for the translational availability of the GRA16 anticancer agent, oncolytic virus (OV) therapy would be a new promising strategy because of its effectiveness against tumor cells and the induction of tumor cell lysis [27]. In reality, talimogene laherparepvec (T-Vec) using oncolytic herpes simplex virus type 1 (HSV-1) has already been approved as the first oncolytic virus drug [27]. Based on this strategy, there is a need to study GRA16/OVs as an anticancer therapeutic in the near future. In conclusion, our results clearly show that GRA16 is a therapeutic agent that can lower NF- $k$ B activation in the treatment of NSCLC with irinotecan. Although further studies are warranted to determine the effects of GRA16 in other cancer types and a possible therapeutic application using OVs for highlighting the translational potential of GRA16, several lines of evidence indicate the anticancer potential of T. gondii GRA16.

\section{Materials and Methods}

\subsection{Cell Culture}

The human NSCLC cell line H1299 was purchased from ATCC (Manassas, VA, USA). Cells were cultured in complete RPMI 1640 medium (WELGENE Inc., Gyeongsan, Korea) containing 10\% fetal bovine serum (FBS; WELGENE Inc.) and 1\% antibiotic-antimycotic solution (WELGENE Inc.) at $37^{\circ} \mathrm{C}$ in a $5 \% \mathrm{CO}_{2}$ incubator.

\subsection{Preparation of GRA16-Expressing Retrovirus Following T. gondii GRA16 Gene Cloning}

GRA16 (ToxoDB database, Gene ID: TGGT1_208830) harboring restriction sites for EcoRI and Sall (underlined) was amplified using polymerase chain reaction (PCR) with the cDNA of T. gondii RH strain and the primers F, 5'-CG GAATTC CGA TGT ATC GAA ACC ACT CA-3' and R, 5'-CC GTCGAC TCA CAT CTG ATC ATT TTT CC-3'. PCR was performed under the following conditions: $95^{\circ} \mathrm{C}$ for $5 \mathrm{~min}$, followed by 35 cycles at $95^{\circ} \mathrm{C}$ for $30 \mathrm{~s}, 58^{\circ} \mathrm{C}$ for $40 \mathrm{~s}$, and $72{ }^{\circ} \mathrm{C}$ for $1.5 \mathrm{~min}$, and a final extension at $72{ }^{\circ} \mathrm{C}$ for $3 \mathrm{~min}$. PCR products (1518 bp) of the GRA16 gene were confirmed via gene sequencing (Cosmo Genetech Co. Ltd., Seoul, Korea). To prepare the expression constructs for GRA16, the pBABE-HAII plasmid (Addgene, Watertown, MA, USA) was digested with EcoRI and SalI and the GRA16 gene was inserted. Platinum-A retrovirus packaging cells (Cell Biolabs Inc., San Diego, CA, USA) were cultured in high-glucose Dulbecco Modified Eagle Medium (DMEM) (WELGENE Inc.) 
and transfected with either pBABE-HA II-GRA16 or pBABE-HAII-Vector using the Lipofectamine 3000 transfection kit (Life Technologies, Carlsbad, NY, USA) and Opti-Minimal Essential Medium (MEM) (Life Technologies, Frederick, MD, USA). Retrovirus-containing supernatants were centrifuged for $10 \mathrm{~min}$ at $2000 \mathrm{rpm}$ and $4{ }^{\circ} \mathrm{C}$ and filtered using $0.45-\mu \mathrm{m}$ syringe filters to obtain stable $\mathrm{H} 1299$ vector-transfected and GRA16-transfected cell lines.

\subsection{Ethics Statement}

All animal experiments were approved by the Institutional Animal Care and Use Committee at Seoul National University (Approved Number SNU-190603-2, 16 July 2019). Mice were maintained in an animal facility according to the standards of the Animal Protection Act and the Laboratory Animal Act in Korea. All mice experiments were conducted according to global standards, such as those established by the Association for Assessment and Accreditation of Laboratory Animal Care International. All efforts were made to minimize animal suffering (Approved Number SNUIBC-R180523-1, 28 June 2018).

\subsection{Confirmation of Stable GRA16 Expression after Establishment of GRA16-Expressing H1299 Stable Cell}

To produce stable GRA16-expressing cells, H1299 cells were treated with pBABE-HA II-GRA16 or pBABE-HA II-Vector retrovirus-containing supernatants and $1 \mu \mathrm{g} / \mathrm{mL}$ of polybrene (Santa Cruz Biotechnology, Santa Cruz, CA, USA) and were cultured for $48 \mathrm{~h}$. Thereafter, retrovirus-infected H1299 cells were selected using $2 \mu \mathrm{g} / \mathrm{mL}$ puromycin (Santa Cruz Biotechnology). Stable GRA16 expression in H1299-GRA16 cells was confirmed using PCR with primers listed in supplementary data (Table 1). The PCR product was analyzed using $0.8 \%$ agarose gel electrophoresis.

Table 1. Primer Sequence Used in Conventional PCR and qRT-PCR.

\begin{tabular}{|c|c|c|}
\hline Gene & Forward Primer Sequence $\left(5^{\prime}-3^{\prime}\right)$ & Reverse Primer Sequence $\left(5^{\prime}-3^{\prime}\right)$ \\
\hline GRA16 & CGGAATTCCGATGTATCGAAACCACTCA & CCGTCGACTCACATCTGATCATTTTTCC \\
\hline pBABE-HA II-Vector & GAGTCGATGTGGAATCCGAC & GGCTTAGGGTGTACAAAGGG \\
\hline CITED2 & TCGTTTTTGTAGCCTTGACATTC & AACAACGAAAAAGACCAAGTTAGC \\
\hline$A B C G 2$ & GTTAAGTGGAAACTGCTGCTTTAGA & TCTGGAGAGTTTTTATCTTTTCAGC \\
\hline CTNNAL1 & AAAGCCAGACAAGCCTGACTCT & AGCAAACCCAGCTTAAGTCCAA \\
\hline$B R C A 1$ & CTACATCAGGCCTTCATCCTG & TTGACCATTCTGCTCCGTTT \\
\hline $\begin{array}{c}P P P 2 R 2 B \\
(P P 2 A-B 55)\end{array}$ & AGCCGGCGCCATTTTGAAAG & GCCGGCAGGATGCTAGATTT \\
\hline CREB1 & GCCCAGGTATCTATGCCAGC & AGTTGAAATCTGAACTGTTTGGAC \\
\hline$S P 1$ & TCATCCGGACACCAACAGTG & TGTTTGGGCTTGTGGGTTCT \\
\hline TFAP4 & TTGCATTCTCCGGCTGATCG & TGAGTCTCGGGGGTTAGTGG \\
\hline$c-M Y C$ & СССТCCACTCGGAAGGACTA & GCTGGTGCATTTTCGGTTGT \\
\hline$B C L 2$ & CTTTGAGTTCGGTGGGGTCA & GGGCCGTACAGTTCCACAAA \\
\hline$B A X$ & СTTTTGCTTCAGGGTTTCATCCAGG & ATCCTCTGCAGCTCCATGTTACTG \\
\hline ARHGEF7 & GCCTGGATAAATACCCTACGC & GGATGGCTTCCGTCAGGAT \\
\hline GAPDH & GGTGAAGTCGGAGTCAACGGA & GAGGGATCTCGCTCCTGGAAGA \\
\hline
\end{tabular}

\subsection{Xenograft Tumor Formation Using Stably Transfected H1299 Cells}

To induce tumor formation, after 1 week of acclimatization of 5-week-old BALB/c nude athymic mice (Orient Bio Inc., Seongnam, Korea), cells $\left(2 \times 10^{6}\right.$ cells $/ 100 \mu \mathrm{L}$ PBS) mixed with $100 \mu \mathrm{L}$ Corning Matrigel Basement Membrane Matrix, Phenol Red-free, LDEV-free (Corning, NY, USA) were subcutaneously injected into the flank of each mouse. After 12 days, tumor sizes and mouse weights of the control, vector, and GRA16 groups ( $n=16$ each) were measured once every 4 days. 
At day 44 after transplantation, the mice were sacrificed and tumor sizes were measured according to lengths (A) and widths (B). Tumor volumes were calculated as $\mathrm{A} \times \mathrm{B}^{2} / 2 \mathrm{~mm}^{2}$ [28].

\subsection{Immunofluorescence of PP2A-B55 in H1299 Stable Cells}

Cells were stained using an anti-PP2A-B55 antibody (Ab) (Santa Cruz Biotechnology) and anti-NF- $\mathrm{kB}$ p65 Ab (Santa Cruz Biotechnology) as primary Abs and goat anti-mouse IgG $(\mathrm{H}+\mathrm{L})$-Alexa Fluor $546 \mathrm{Ab}$ (Thermo Fisher Scientific, Waltham, MA, USA) as the secondary Ab; the nucleus was stained using 4',6-diamidino-2-phenylindole (Life Technologies, Carlsbad, CA, USA). Fluorescence imaging was performed using the DE/DMI6000B inverted fluorescence microscope (Leica, Hessen, Germany).

\subsection{Co-IP of GRA16 and PP2A-B55}

For the Co-IP assay, total proteins were isolated from $2 \times 10^{6}$ cells from each experimental group (control, vector, and GRA16) using $600 \mu \mathrm{L}$ of M-PER mammalian protein extraction reagent (Pierce Biotechnology Inc., Rockford, IL, USA). Protein A/G-plus agarose beads (Santa Cruz Biotechnology) were pre-reacted with the anti-HA tag Ab (Cell signaling technology, Danvers, MA, USA) and incubated with $0.5 \mathrm{mg}$ protein extracts for $4 \mathrm{~h}$ at $4{ }^{\circ} \mathrm{C}$. Thereafter, supernatants were analyzed via Western blotting using the anti-PP2A-B55 Ab (Santa Cruz Biotechnology).

\subsection{Real-Time PCR}

The expression levels of various target mRNAs were investigated using the SYBR Green I detection chemistry (Bio-Rad Laboratories, Berkeley, CA, USA) with the CFX96 Real-time PCR detection system (Bio-Rad Laboratories). The primer sequences are listed in Table 1. Real-time PCR data were analyzed using the $\mathrm{iQ}^{\mathrm{TM}} 5$ optical system software (Bio-Rad Laboratories). Data were expressed as fold changes in gene expression in vector and GRA16 groups compared with the corresponding control group for each target gene after normalizing to the $\mathrm{Ct}$ values of the GAPDH gene.

\subsection{Chemicals and Their $I C_{50}$}

To determine the $\mathrm{IC}_{50}$ values of irinotecan (CPT-11; LC Laboratories, Woburn, MA, USA) and LB-100 (Selleckchem, Houston, TX, USA), completely starved H1299 cells were seeded into 96-well plates at $3 \times 10^{3}$ cells/well and incubated for $24 \mathrm{~h}$ in 10\% FBS-RPMI 1640 medium. Subsequently, irinotecan or LB-100 was added at concentrations of $0-100 \mu \mathrm{M}$, and the cells were incubated for $48 \mathrm{~h}$. Cell viability was investigated using the CCK-8 assay (Dojindo, Rockville, MD, USA).

\subsection{Western Blotting}

The expression levels of NF- $\mathrm{kB}$ pathway-related proteins were investigated using Western blotting analyses of cells harvested at $0,24,48$, and $72 \mathrm{~h}$ after treatment with $17 \mu \mathrm{M}$ irinotecan or $7 \mu \mathrm{M}$ LB-100. Total proteins were extracted using the M-PER mammalian protein extraction kit (Pierce Biotechnology Inc.), and cytoplasmic and nuclear fractions of cells were extracted using the NE-PER Nuclear and Cytoplasmic Extraction kits (Thermo Fisher Scientific, Waltham, MA, USA). Proteins separated via SDS-PAGE were transferred on to polyvinylidene fluoride membranes (Merck Millipore, Burlington, MA, USA) at $100 \mathrm{~V}$ for $1 \mathrm{~h}$ at $4{ }^{\circ} \mathrm{C}$ using the Mini Trans-Blot ${ }^{\circledR}$ Electrophoretic Transfer Cell (Bio-Rad Laboratories) instrument. Membranes were then immunostained with the following specific primary antibodies from Santa Cruz Biotechnology, Inc.: anti-HA tag $\mathrm{Ab}$, anti- $\beta$-Actin $\mathrm{Ab}$, anti-PP2A-B55 Ab, anti-Cyclin B1 Ab, anti-ENSA Ab, anti-IKK $\beta$ Ab, anti-p-IkB $\alpha$ (Ser32) Ab, anti-I $\kappa \mathrm{B} \alpha \mathrm{Ab}$, anti-NF- $\mathrm{kB}$ p65 Ab, and anti-Lamin B Ab; Abcam, Inc. (Cambridge, MA, USA): anti-GWL Ab; Affinity, Inc.: anti-p-ENSA (Ser67) Ab; Cell signaling technology, Inc.: anti-AKT Ab and anti-p-AKT (Thr308) Ab; and Enzo Life Sciences, Inc. (Doral, FL, USA): anti-ERK1/2 Ab and anti-p-ERK1/2 (Thr202/Tyr204) Ab. Horseradish peroxidase (HRP)-conjugated secondary Abs 
were from Santa Cruz Biotechnology, Inc: goat anti-mouse IgG-HRP Ab, chicken anti-rabbit IgG-HRP Ab, and donkey anti-goat IgG-HRP Ab. Protein bands were then visualized using enhanced chemiluminescence kits (Pierce Biotechnology Inc.), and images were captured using Amersham Imager 600 (GE healthcare, Chicago, IL, USA). Signal intensities were calculated using ImageJ.

\subsection{Cell Proliferation and Viability}

After starving the cells in 1\% FBS-RPMI 1640 medium for $48 \mathrm{~h}$ to synchronize the cell cycle, cells were seeded into 96-well plates at $3 \times 10^{3}$ cells/well and incubated for $0,24,48$, and $72 \mathrm{~h}$. Cell viability was analyzed using the CCK- 8 assay. Optical density was measured at $450 \mathrm{~nm}$ using a microplate reader (Thermo Fisher Scientific). Changes in cell numbers were also monitored by counting the cells using a Trypsin-Ethylenediaminetetraacetic acid (EDTA) solution (Thermo Fisher Scientific).

\subsection{Analysis of Apoptosis and Cell Cycle via Flow Cytometry}

FACS analysis was used to analyze apoptosis and cell cycle transitions. For apoptosis analysis, cells were incubated for $72 \mathrm{~h}$ in 10\% FBS-RPMI 1640 medium with and without irinotecan. Cells were harvested using the Trypsin-EDTA solution and the cell pellets were resuspended in $100 \mu \mathrm{L}$ Annexin $\mathrm{V}$ binding buffer (BD Pharmingen, Holbrook, NJ, USA), followed by staining with both $5 \mu \mathrm{L}$ of Annexin V-APC (Biolegend, San Diego, CA, USA) and $5 \mu \mathrm{L}$ of PI solution $(50 \mu \mathrm{g} / \mathrm{mL})$ (BD Pharmingen). Data were analyzed based on the proportions of cells in Annexin V-APC (X-axis) and PI (Y-axis) using BD CellQuest (Becton Dickinson). Likewise, for cell cycle analysis, the starved cells were incubated for $48 \mathrm{~h}$. Fixed cells were washed and resuspended in $200 \mu \mathrm{L}$ of a PI (Sigma-Aldrich, St. Louis, MO, USA) solution containing $3.8 \mathrm{mM}$ sodium citrate, $50 \mu \mathrm{g} / \mathrm{mL}$ PI, and $100 \mu \mathrm{g} / \mathrm{mL}$ RNase A (Sigma-Aldrich) and incubated at $4{ }^{\circ} \mathrm{C}$ for $20 \mathrm{~min}$ in the dark. Cell cycle phases were analyzed using FACS Calibur-P (Becton Dickinson, Franklin Lakes, NJ, USA). Data were acquired by linear amplification of FL2-A and analyzed for proportions of cells in the sub- $G_{1}, G_{1}, S$, and $G_{2} / M$ phases using BD CellQuest (Becton Dickinson).

\subsection{Statistical Analysis}

All statistical analyses were performed using Microsoft Excel and GraphPad Prism 5 (GraphPad, San Diego, CA, USA). Data are presented as mean and standard deviation (SD) of three independent experiments performed in triplicate. Time-dependent differences after irinotecan treatments were identified using one-way analysis of variance (ANOVA) followed by Dunnett's multiple-comparison test. Differences between experimental groups (control, vector, and GRA16) were identified using ANOVA followed by Turkey's multiple-comparison tests. Significant differences between experimental groups were identified using two-way ANOVA followed by Bonferroni post-hoc comparison tests.

Author Contributions: S.-H.S. and E.-H.S. conceived and designed the experiments. S.-H.S. and S.-G.K. prepared the GRA16-stable cell line. S.-H.S. performed molecular experiments. S.-H.S., J.-H.S., and D.-W.H. analyzed the data. E.-H.S. contributed to reagents/materials/analytical tools. E.-H.S. supported the idea and was responsible for overall project administration, acquiring financial support, and writing the paper. All authors have read and agreed to the published version of the manuscript.

Funding: This research was funded by the Basic Science Research Program of the National Research Foundation of Korea funded by the Ministry of Education, Science and Technology, grant number NRF-2018R1D1A1B07050517 and the Seoul National University Bundang Hospital Research Fund, grant number 02-2018-010.

Conflicts of Interest: The authors declare no conflict of interest. The funders had no role in the design of the study; in the collection, analyses, or interpretation of data; in the writing of the manuscript, or in the decision to publish the results. 


\section{Abbreviations}

$\begin{array}{ll}\text { ABCG2 } & \text { ATP-binding cassette super-family G member 2 } \\ \text { AKT(=PKB) } & \text { Serine/threonine kinase (Protein kinase B) } \\ \text { ARHGEF7 } & \text { Rho Guanine Nucleotide Exchange Factor 7 } \\ \text { BAX } & \text { Bcl-2-associated X protein } \\ \text { BCL-2 } & \text { B-cell lymphoma 2 } \\ \text { BRCA1 } & \text { Breast cancer type 1 } \\ \text { CITED2 } & \text { Cbp/p300-interacting transactivator 2 } \\ \text { c-MYC } & \text { Cellular-Myelocytomatosis } \\ \text { COPD } & \text { Chronic obstructive pulmonary disease } \\ \text { CREB1 } & \text { CAMP responsive element binding protein 1 } \\ \text { CTNNAL1 } & \text { Catenin alpha like 1 } \\ \text { ENSA } & \text { Endosulfine-alpha } \\ \text { ERK } & \text { Extracellular signal-regulated kinase } \\ \text { GRA16 } & \text { Dense granule protein 16 } \\ \text { GWL } & \text { Greatwall } \\ \text { HAUSP } & \text { Herpesvirus-associated ubiquitin-specific protease } \\ \text { IKK } \beta & \text { Inhibitory kappa B kinase beta } \\ \text { IkB } \alpha & \text { Inhibitor of kappa B alpha } \\ \text { NF- } \text { BB } & \text { Nuclear factor kappa-light-chain-enhancer of activated B cells } \\ \text { NSCLC } & \text { Non-small-cell lung cancer } \\ \text { PP2A-B55 } & \text { Protein phosphatase 2A-regulatory subunit B55 } \\ \text { PTEN } & \text { Phosphatase and tensin homolog } \\ \text { PV } & \text { Parasitophorous vacuole } \\ \text { SP1 } & \text { Specificity protein 1 } \\ \text { T. gondii } & \text { Toxoplasma gondii } \\ \text { TFAP4 } & \text { Transcription factor activating enhancer binding protein 4 } \\ \text { Topo-I } & \text { Topoisomerase-1 } \\ & \end{array}$

\section{References}

1. Chang, A. Chemotherapy, chemoresistance and the changing treatment landscape for NSCLC. Lung Cancer 2011, 71, 3-10. [CrossRef]

2. Mogi, A.; Kuwano, H. TP53 mutations in nonsmall cell lung cancer. BioMed Res. Int. 2011, 2011, 583929. [CrossRef] [PubMed]

3. Zarogoulidis, K.; Zarogoulidis, P.; Darwiche, K.; Boutsikou, E.; Machairiotis, N.; Tsakiridis, K.; Katsikogiannis, N.; Kougioumtzi, I.; Karapantzos, I.; Huang, H.; et al. Treatment of non-small cell lung cancer (NSCLC). J. Thorac. Dis. 2013, 5, S389-S396. [PubMed]

4. Godwin, P.; Baird, A.M.; Heavey, S.; Barr, M.P.; O’Byrne, K.J.; Gately, K.A. Targeting nuclear factor-kappa B to overcome resistance to chemotherapy. Front. Oncol. 2013, 3, 120. [CrossRef] [PubMed]

5. Gu, J.; Zhou, Y.; Huang, L.; Ou, W.; Wu, J.; Li, S.; Xu, J.; Feng, J.; Liu, B. TP53 mutation is associated with a poor clinical outcome for non-small cell lung cancer: Evidence from a meta-analysis. Mol. Clin. Oncol. 2016, 5, 705-713. [CrossRef]

6. Chen, W.; Li, Z.; Bai, L.; Lin, Y. NF-kappaB, a mediator for lung carcinogenesis and a target for lung cancer prevention and therapy. Front. Biosci. 2011, 16, 1172-1185. [CrossRef]

7. Huang, T.T.; Wuerzberger-Davis, S.M.; Seufzer, B.J.; Shumway, S.D.; Kurama, T.; Boothman, D.A.; Miyamoto, S. NF-kappaB activation by camptothecin. A linkage between nuclear DNA damage and cytoplasmic signaling events. J. Biol. Chem. 2000, 275, 9501-9509. [CrossRef]

8. Xu, Y.; Villalona-Calero, M.A. Irinotecan: Mechanisms of tumor resistance and novel strategies for modulating its activity. Ann. Oncol. 2002, 13, 1841-1851. [CrossRef]

9. Rothenberg, M.L. Irinotecan (CPT-11): Recent developments and future directions-Colorectal cancer and beyond. Oncologist 2001, 6, 66-80. [CrossRef] 
10. Kim, S.G.; Seo, S.H.; Shin, J.H.; Yang, J.P.; Lee, S.H.; Shin, E.H. Increase in the nuclear localization of PTEN by the Toxoplasma GRA16 protein and subsequent induction of p53-dependent apoptosis and anticancer effects. J. Cell. Mol. Med. 2019, 23, 3234-3245. [CrossRef]

11. Bougdour, A.; Durandau, E.; Brenier-Pinchart, M.P.; Ortet, P.; Barakat, M.; Kieffer, S.; Curt-Varesano, A.; Curt-Bertini, R.L.; Bastien, O.; Coute, Y.; et al. Host cell subversion by Toxoplasma GRA16, an exported dense granule protein that targets the host cell nucleus and alters gene expression. Cell Host Microbe 2013, 13, 489-500. [CrossRef] [PubMed]

12. Barisic, S.; Strozyk, E.; Peters, N.; Walczak, H.; Kulms, D. Identification of PP2A as a crucial regulator of the NF-kB feedback loop: Its inhibition by UVB turns NF- KB into a pro-apoptotic factor. Cell Death Differ. 2008, 15, 1681-1690. [CrossRef] [PubMed]

13. Bougdour, A.; Tardieux, I.; Hakimi, M.A. Toxoplasma exports dense granule proteins beyond the vacuole to the host cell nucleus and rewires the host genome expression. Cell. Microbiol. 2014, 16, 334-343. [CrossRef] [PubMed]

14. Besteiro, S. Toxoplasma control of host apoptosis: The art of not biting too hard the hand that feeds you. Microb. Cell 2015, 2, 178-181. [CrossRef]

15. Bai, D.; Ueno, L.; Vogt, P.K. Akt-mediated regulation of NFkB and the essentialness of NF- $k B$ for the oncogenicity of PI3K and Akt. Int. J. Cancer 2009, 125, 2863-2870. [CrossRef]

16. Ikeda, R.; Vermeulen, L.C.; Lau, E.; Jiang, Z.; Pomplun, M.; Kolesar, J.M. Establishment and characterization of irinotecan-resistant human non-small cell lung cancer A549 cells. Mol. Med. Rep. 2010, 3, 1031-1034.

17. Nader, C.P.; Cidem, A.; Verrills, N.M.; Ammit, A.J. Protein phosphatase 2A (PP2A): A key phosphatase in the progression of chronic obstructive pulmonary disease (COPD) to lung cancer. Respir. Res. 2019, 20, 222. [CrossRef]

18. Ruvolo, P.P. The broken "off" switch in cancer signaling: PP2A as a regulator of tumorigenesis, drug resistance, and immune surveillance. BBA Clin. 2016, 6, 87-99. [CrossRef]

19. Li, Y.; Ahmed, F.; Ali, S.; Philip, P.A.; Kucuk, O.; Sarkar, F.H. Inactivation of nuclear factor кB by soy isoflavone genistein contributes to increased apoptosis induced by chemotherapeutic agents in human cancer cells. Cancer Res. 2005, 65, 6934-6942. [CrossRef]

20. Gong, L.; Li, Y.; Nedeljkovic-Kurepa, A.; Sarkar, F.H. Inactivation of NF-кB by genistein is mediated via Akt signaling pathway in breast cancer cells. Oncogene 2003, 22, 4702-4709. [CrossRef]

21. Li, Y.; Upadhyay, S.; Bhuiyan, M.; Sarkar, F.H. Induction of apoptosis in breast cancer cells MDA-MB-231 by genistein. Oncogene 1999, 18, 3166-3172. [CrossRef] [PubMed]

22. Pyo, K.H.; Jung, B.K.; Xin, C.F.; Lee, Y.W.; Chai, J.Y.; Shin, E.H. Prominent IL-12 production and tumor reduction in athymic nude mice after Toxoplasma gondii lysate antigen treatment. Korean J. Parasitol. 2014, 52, 605-612. [CrossRef]

23. Pyo, K.H.; Lee, Y.W.; Lim, S.M.; Shin, E.H. Immune adjuvant effect of a Toxoplasma gondii profilin-like protein in autologous whole-tumor-cell vaccination in mice. Oncotarget 2016, 7, 74107-74119. [CrossRef]

24. Pyo, K.H.; Jung, B.K.; Chai, J.Y.; Shin, E.H. Suppressed CD31 expression in sarcoma-180 tumors after injection with Toxoplasma gondii lysate antigen in BALB/c mice. Korean J. Parasitol. 2010, 48, 171-174. [CrossRef] [PubMed]

25. Lima, T.S.; Lodoen, M.B. Mechanisms of human innate immune evasion by Toxoplasma gondii. Front. Cell. Infect. Microbiol. 2019, 9, 103. [CrossRef]

26. Wang, J.; Cui, L.; Feng, L.; Zhang, Z.; Song, J.; Liu, D.; Jia, X. Isoalantolactone inhibits the migration and invasion of human breast cancer MDA-MB-231 cells via suppression of the $\mathrm{p} 38 \mathrm{MAPK} / \mathrm{NF}-\mathrm{kB}$ signaling pathway. Oncol. Rep. 2016, 36, 1269-1276. [CrossRef]

27. Raja, J.; Ludwig, J.M.; Gettinger, S.N.; Schalper, K.A.; Kim, H.S. Oncolytic virus immunotherapy: Future prospects for oncology. J. Immunother. Cancer 2018, 6, 140. [CrossRef]

28. Carlsson, G.; Gullberg, B.; Hafström, L.O. Estimation of liver tumor volume using different formulas-An experimental study in rats. J. Cancer Res. Clin. Oncol. 1983, 105, 20-23. [CrossRef] [PubMed]

(C) 2020 by the authors. Licensee MDPI, Basel, Switzerland. This article is an open access article distributed under the terms and conditions of the Creative Commons Attribution (CC BY) license (http://creativecommons.org/licenses/by/4.0/). 